\title{
Protective Role of Transduced Tat-Thioredoxin1 (Trx1) against Oxidative Stress-Induced Neuronal Cell Death via ASK1-MAPK Signal Pathway
}

\author{
Eun Ji Yeo ${ }^{1, \dagger}$, Won Sik Eum ${ }^{1, \dagger}$, Hyeon Ji Yeo ${ }^{1}$, Yeon Joo Choi ${ }^{1}$, Eun Jeong Sohn', Hyun Jung Kwon ${ }^{2}$, \\ Dae Won Kim², Duk-Soo Kim ${ }^{3}$, Sung-Woo Cho ${ }^{4}$, Jinseu Park ${ }^{1}$, Kyu Hyung Han ${ }^{1}$, Keun Wook Lee', \\ Jong Kook Park ${ }^{1}$, Min Jea Shin ${ }^{1, *}$ and Soo Young Choi ${ }^{1, *}$ \\ ${ }^{1}$ Department of Biomedical Science and Research Institute of Bioscience and Biotechnology, Hallym University, Chuncheon 24252, \\ ${ }^{2}$ Department of Biochemistry and Molecular Biology, Research Institute of Oral Sciences, College of Dentistry, Gangneung-Wonju \\ National University, Gangneung 25457, \\ ${ }^{3}$ Department of Anatomy and BK21 Plus Center, College of Medicine, Soonchunhyang University, Cheonan 31538, \\ ${ }^{4}$ Department of Biochemistry and Molecular Biology, University of Ulsan College of Medicine, Seoul 05505, Republic of Korea
}

\begin{abstract}
Oxidative stress plays a crucial role in the development of neuronal disorders including brain ischemic injury. Thioredoxin 1 (Trx 1 ), a $12 \mathrm{kDa}$ oxidoreductase, has anti-oxidant and anti-apoptotic functions in various cells. It has been highly implicated in brain ischemic injury. However, the protective mechanism of Trx1 against hippocampal neuronal cell death is not identified yet. Using a cell permeable Tat-Trx1 protein, protective mechanism of Trx1 against hydrogen peroxide-induced cell death was examined using HT-22 cells and an ischemic animal model. Transduced Tat-Trx1 markedly inhibited intracellular ROS levels, DNA fragmentation, and cell death in $\mathrm{H}_{2} \mathrm{O}_{2}$-treatment HT-22 cells. Tat-Trx1 also significantly inhibited phosphorylation of ASK1 and MAPKs in signaling pathways of HT-22 cells. In addition, Tat-Trx1 regulated expression levels of Akt, NF- $\mathrm{KB}$, and apoptosis related proteins. In an ischemia animal model, Tat-Trx1 markedly protected hippocampal neuronal cell death and reduced astrocytes and microglia activation. These findings indicate that transduced Tat-Trx1 might be a potential therapeutic agent for treating ischemic injury.
\end{abstract}

Key Words: Tat-Trx1, ASK1, ROS, Apoptosis, Ischemia, Protein therapy

\section{INTRODUCTION}

There is some evidence that oxidative stress plays a crucial role in neuronal disorders including brain ischemic injury. Production of large amounts of reactive oxygen species (ROS) can trigger oxidative stress and lead to dysfunction of cells due to DNA and protein damage. Finally, overproduction of ROS could lead to cell death. Although ROS have beneficial roles in regulating cellular signaling pathways, overproduction of ROS is involved in brain ischemic injury (Floyd, 1990; Li et al., 2011; Mates et al., 2012; Sinha et al., 2013; Leak et al., 2015; Li and Zhang, 2015). Therefore, some studies have suggested that inhibiting overproduction of ROS is important to prevent neuronal death in brain ischemic injury (Ginsberg et al., 2003; Sugawara and Chan, 2003).

Thioredoxin 1 (Trx1), a small (12 kDa) protein, is one of cellular redox enzymes ubiquitously expressed in mammalian cells. Trx1 has a variety of biological functions, including regulating cell growth and apoptosis as an antioxidant protein (Haendeler et al., 2002; Kamimoto et al., 2010). Several studies have shown that Trx1 protein can prevent cells against oxidative stress such as superoxide and hydrogen peroxide $\left(\mathrm{H}_{2} \mathrm{O}_{2}\right)$-induced toxicity and apoptosis induced by ROS (Saitoh et al., 1998; Ueda et al., 2002; Yoshida et al., 2003; Nadeau et al., 2007). Although Trx1 protein plays beneficial roles in cells as an antioxidant protein, the protective mechanism of Trx1 against ischemic injury remains unclear.

Mitogen activated protein kinases (MAPKs) including ex-

\section{Open Access https://doi.org/10.4062/biomolther.2020.154}

This is an Open Access article distributed under the terms of the Creative Commons Attribution Non-Commercial License (http://creativecommons.org/licenses/by-nc/4.0/) which permits unrestricted non-commercial use, distribution, and reproduction in any medium, provided the original work is properly cited.
Received Sep 3, 2020 Revised Nov 23, 2020 Accepted Dec 10, 2020 Published Online Jan 13, 2021

\section{*Corresponding Authors}

E-mail: wehome3@hallym.ac.kr (Shin MJ), sychoi@hallym.ac.kr (Choi SY) Tel: +82-33-248-2112 (Shin MJ), +82-33-248-2112 (Choi SY) Fax: +82-33-241-1463 (Shin MJ), +82-33-241-1463 (Choi SY)

${ }^{\dagger}$ The first two authors contributed equally to this work. 
tracellular signal-regulated kinase (ERK), c-Jun $\mathrm{N}$-terminal kinase (JNK), and some proteins in p38 signaling pathways are involved in cell growth, proliferation and apoptosis (Ang et al., 2016). MAPKs signaling pathways are activated by ROS. They are pivotal signaling pathways that can lead to neuronal cell death (Jellinger and Stadelmann, 2001; Kim and Choi, 2010; Yu et al., 2016; Zhang et al., 2016). Apoptosissignal regulating kinase 1 (ASK1) is located at the upstream of MAPKs. It can phosphorylate MAPKs (JNK and p38). ASK1 is known as an important component in oxidative stress-induced apoptosis. The ASK1-MAPK cascade has emerged as a key cell death pathway in response to oxidative stress (Ichijo et al., 1997; Shiizaki et al., 2013).

Protein transduction domain (PTD) is known as an effective tool for delivering proteins into cells. Thus, PTDs including Tat PTD have been used to delivery therapeutic proteins into cells and tissues (Schwarze et al., 1999; Wadia and Dowdy, 2002; van den Berg and Dowdy, 2011). Many studies have reported protective effects of various transduced PTD fusion proteins against cell death both in vitro and in vivo (Embury et al., 2001; Kubo et al., 2008; Shin et al., 2014; Kim et al., 2015; Kim et al., 2018; Yeo et al., 2018, 2019). In this study, we showed that Tat-Trx1 protein transduced into neuronal cells and brain tissues of an ischemia mice model significantly protected against hippocampal neuronal cell death.

\section{MATERIALS AND METHODS}

\section{Materials and HT-22 cell culture}

$\mathrm{Ni}^{2+}$-nitrilotriacetic acid Sepharose Superflow was purchased from Qiagen (Valencia, CA, USA). PD-10 columns were purchased from Amersham (Brauncschweig, Germany). Fetal bovine serum (FBS) and antibiotics (streptomycin and penicillin) were obtained from Gibco BRL (Grand Island, NY, USA). Dulbecco's modified Eagle's medium (DMEM) was obtained from Lonza/BioWhittaker (Walkersville, MD, USA). 2',7'-Dichlorofluorescein diacetate (DCF-DA) was purchased from Sigma-Aldrich (St. Louis, MO, USA). Histidine antibody was purchased from Santa Cruz Biotechnology (Santa Cruz, CA, USA). The indicated antibodies were obtained from Cell Signaling Technology (Beverly, MA, USA). Unless otherwise stated, all other agents were of the highest grade available.

Mouse hippocampal HT-22 cells were grown in Dulbecco's modified Eagle's medium (DMEM) containing 10\% fetal bovine serum (FBS) and antibiotics $(100 \mu \mathrm{g} / \mathrm{mL}$ streptomycin, $100 \mu \mathrm{g} / \mathrm{mL}$ penicillin) at $37^{\circ} \mathrm{C}$ in a humidity chamber with $5 \%$ $\mathrm{CO}_{2}$ and $95 \%$ air.

\section{Purification and transduction of Tat-Trx 1 proteins into HT-22 cells}

Preparation of the Tat expression vector has been described in a previous study (Shin et al., 2014; Kim et al., 2015). Human Trx1 was amplified by PCR using the sense primer 5'-CTCGAGATGGTGAAGCAGATCG-3' which contained an Xhol restriction site and the antisense primer 5'-GGATCCTTAGACTAATTCATTAATGGTGG-3' which contained a BamHI restriction site. The resulting $P C R$ products were ligated into a TA vector ( $p G \mathrm{ME}^{\circledR}-\mathrm{T}$ easy vector; Promega Corporation, Madison, WI, USA) and digested with $\mathrm{Xhol}$ and BamHI restriction enzymes. Fragments were then ligated into the Tat expression vector to generate Tat-Trx1 protein. Trx1 protein was prepared without the Tat peptide. Subsequently, Tat-Trx1 and Trx1 protein were expressed in Escherichia coli BL21 (DE3) cells by adding $0.5 \mathrm{mM}$ isopropyl- $\beta$-D-thiogalactoside (Duchefa, Haarlem, the Netherlands) at $37^{\circ} \mathrm{C}$ for $6 \mathrm{~h}$. Then, Tat-Trx 1 and Trx 1 protein was purified using a $\mathrm{Ni}^{2+}$-nitrilotriacetic acid Sepharose affinity column and PD-10 column chromatography according to the manufacturer's instructions. Tat-Trx1 and Trx1 protein concentration was determined by the Bradford assay (Bradford, 1976).

To examine Tat-Trx1 protein transduction efficiency, HT-22 cells were cultured in a $60 \mathrm{~mm}$ dish plate and exposed to different concentrations of Tat-Trx1 and Trx1 protein (0.5-5 $\mu \mathrm{M})$ for $1 \mathrm{~h}$ or over various time periods (10-100 $\mathrm{min}$ ) of Tat-Trx1 and Trx1 protein $(5 \mu \mathrm{M})$. The cells were treated with trypsinEDTA (Gibco BRL) and washed twice with phosphate-buffered saline (PBS). To determine the intracellular stability of transduced Tat-Trx1 protein, cells were cultured over various time periods (1-24 h) after Tat-Trx1 protein transduction. We confirmed the transduced levels of Tat-Trx1 protein which were measured by Western blot analysis and fluorescence microscopy analysis using an anti-His antibody.

\section{Western blot analysis}

After transduction of Tat-Trx1 protein, protein extraction was performed using cell lysis buffer (RIPA; ELPIS BIOTECH, Daejeon, Korea) according to the manufacturer's instructions. Then, equal amount of proteins were loaded into 15\% SDSPAGE and electrotransferred to a polyvinylidene difluoride (PVDF) membrane. The membrane was blocked with TBS-T (25 mM Tris- $\mathrm{HCl}, 140 \mathrm{mM} \mathrm{NaCl}, 0.1 \%$ Tween 20, pH 7.5) buffer containing $5 \%$ non-fat dry milk or BSA for $1 \mathrm{~h}$. After being washed with TBS-T buffer, the membrane was incubated with the indicated primary antibodies and horseradish peroxidaseconjugated secondary antibodies. Then the membranes were washed with TBS-T buffer three times and the protein bands were identified using chemiluminescent reagents as recommended by the manufacturer (Amersham, Franklin Lakes, NJ, USA) (Shin et al., 2014; Jegal et al., 2019).

\section{Confocal fluorescence microscopy analysis}

To determine the intracellular distribution of transduced TatTrx1 protein in HT-22 cells, we performed confocal fluorescence microscopy as described previously (Shin et al., 2014; Yeo et al., 2019). HT-22 cells were placed on coverslips and treated with $5 \mu \mathrm{M}$ of Tat-Trx 1 protein for $1 \mathrm{~h}$. The cells were washed with PBS twice and fixed with $4 \%$ paraformaldehyde for $5 \mathrm{~min}$. The cells were treated in PBS containing 3\% bovine serum albumin and $0.1 \%$ Triton X-100 (PBS-BT) at room temperature for $30 \mathrm{~min}$ and washed with PBS-BT. The histidine primary antibody was diluted 1:1,500 and incubated at room temperature for $3 \mathrm{~h}$. The Alexa fluor 488-conjugated secondary antibody (Invitrogen, Carlsbad, CA, USA) was diluted $1: 1,500$ and incubated in the dark for $1 \mathrm{~h}$. Nuclei were stained with $1 \mu \mathrm{g} / \mathrm{mL}$ DAPI (Roche Applied Science, Mannheim, Germany) for $2 \mathrm{~min}$. Then stained cells were analyzed by confocal fluorescence microscopy using a confocal laser-scanning system (MRC1024, Bio-Rad, CA, USA).

\section{Cell viability assay}

A cell viability assay was performed using a water-soluble tetrazolium salt-1 (WST-1) cytotoxicity assay (EZ-Cytox cell viability assay kit, Daeil Lab service Co., Seoul, Korea) accord- 
ing to the manufacturer's protocols (Shin et al., 2014; Jegal et al., 2019). HT-22 cells were seeded into 96-well plates and treated with Tat-Trx1 (1-5 $\mu \mathrm{M})$ and Trx1 for $1 \mathrm{~h}$. Then, the cells were incubated with $700 \mu \mathrm{M}$ hydrogen peroxide $\left(\mathrm{H}_{2} \mathrm{O}_{2}\right)$ for 1 h $30 \mathrm{~min}$. The absorbance was measured at $450 \mathrm{~nm}$ using an ELISA microplate reader (Multiskan MCC/340; Thermo Labsystems, Helsinki, Finland). Cell viability was defined as the \% of untreated control cells.

\section{Measurement of intracellular reactive oxygen species (ROS) levels}

Intracellular ROS levels were determined using 2',7'-Dichlorofluorescein diacetate (DCF-DA) as described previously (Shin et al., 2014; Kim et al., 2019; Yeo et al., 2019). ROS levels in the HT-22 cells were determined in the presence or absence of Tat-Trx 1 protein $(5 \mu \mathrm{M})$. After $1 \mathrm{~h}$ of pre-treatment with Tat-Trx1 protein, the cells were treated with $\mathrm{H}_{2} \mathrm{O}_{2}(700$ $\mu \mathrm{M})$ for $30 \mathrm{~min}$. Following a PBS wash, the cells were treated with $20 \mu \mathrm{M}$ DCF-DA for $20 \mathrm{~min}$. Then, fluorescent images were obtained by fluorescence microscopy (Eclipse 80i, Nikon, Tokyo, Japan) and the fluorescence intensity was detected with excitation at $485 \mathrm{~nm}$ and emission at $538 \mathrm{~nm}$ using a Fluoroskan ELISA plate reader (Thermo Labsystems).

\section{TUNEL assay}

To examine whether transduced Tat-Trx1 protein protects against $\mathrm{H}_{2} \mathrm{O}_{2}$-induced DNA damage in cells, HT-22 cells were pretreated with $5 \mu \mathrm{M}$ Tat-Trx1 protein for $1 \mathrm{~h}$ and exposed to $700 \mu \mathrm{M} \mathrm{H}_{2} \mathrm{O}_{2}$ for $6 \mathrm{~h}$. DNA fragmentation was determined using a Cell Death Detection Kit (Roche Applied Science, Basel, Switzerland) according to the manufacturer's instructions. Fluorescent images were obtained by fluorescence microscopy (Eclipse 80i, Nikon) and the fluorescence intensity was detected with excitation at $485 \mathrm{~nm}$ and emission at $538 \mathrm{~nm}$ using a Fluoroskan ELISA plate reader (Thermo Labsystems) (Shin et al., 2014; Yeo et al., 2019).

\section{Measurement of MAPKs and apoptotic protein expression}

HT-22 cells were incubated in the absence or presence of Tat-Trx1 $(5 \mu \mathrm{M})$ for $1 \mathrm{~h}$, and then treated with $\mathrm{H}_{2} \mathrm{O}_{2}$ for various times. The expression of Akt, MAPKs and apoptotic protein expression levels were determined by Western blotting using indicated specific antibodies. The bands were quantified by Image $\mathrm{J}$ software (NIH, Bethesda, MD, USA) (Shin et al., 2014).

\section{Experimental animals}

Male gerbils (65-75 g; 6 months old) obtained from the Experimental Animal Center, at Hallym University (Chuncheon, Korea) were housed at a temperature of $23^{\circ} \mathrm{C}$, with humidity of $60 \%$, and exposed to 12 hour periods of light and dark with free access to food and water. All experimental procedures involving animals and their care conformed to the Guide for the Care and Use of Laboratory Animals of the National Veterinary Research \& Quarantine Service of Korea and were approved by the Institutional Animal Care and Use Committee of Soonchunhyang University (Cheonan, Korea) [SCH 15-0002-3].

The transient forebrain ischemia model was performed as described previously (Shin et al., 2014; Yeo et al., 2019). Briefly, the animals were anesthetized, common carotid arteries were isolated, freed of nerve fibers, and occluded with non-traumatic aneurysm clips. Complete interruption of blood flow was confirmed by observing the retinal artery using an ophthalmoscope. After 5 min occlusion, the aneurysm clips were removed. The restoration of blood flow (reperfusion) was observed directly under the ophthalmoscope.

To explore the protective effects of Tat-Trx1 protein against ischemic damage, the animals were divided into 5 groups (each $n=10$ ): control sham group, vehicle-treated group, TatTrx1-treated group, Trx1-treated group and Tat peptide-treated group. The Tat-Trx 1 proteins, Trx 1 proteins and Tat peptide ( $2 \mathrm{mg} / \mathrm{kg}$ ) were administered intraperitoneally $30 \mathrm{~min}$ before ischemia-reperfusion. The brains from each group were harvested and the levels of 4-hydroxynonenal (4-HNE) and endogenous Trx1 proteins were determined by Western blot analysis using 4-HNE (Santa Cruz, CA, USA) and Trx1 (Cell Signaling Technology) antibodies. Also, intracellular ROS level was determined using a ROS assay kit (Thermo Fisher Scientific, Waltham, MA, USA) according to the manufacturer's instructions.

\section{Immunohistochemical analysis}

Immunohistochemistry was performed as described in previous studies (Shin et al., 2014; Yeo et al., 2019). Brain tissue samples were obtained at 7 days after ischemia-reperfusion. To examine the protective effects of transduced Tat-Trx 1 protein against ischemic damage, the sections were incubated in $10 \%$ normal goat serum in PBS for 30 min and the sections were stained with a histidine antibody, Cresyl violet (CV), Fluoro-Jade B (F-JB), ionized calcium-binding adapter molecule 1 (Iba-1) and glial fibrillary acidic protein (GFAP).

The positive neuronal cell number and intensity of immunoreactivity were calculated using an image analyzing system equipped with a computer based CCD camera (software: Optimas 6.5, CyberMetrics, Scottsdale, AZ, USA). The staining intensity of the immunoreactive structures was evaluated as the relative optical density (ROD). A ratio of the ROD was calibrated as \% (Shin et al., 2014; Yeo et al., 2019).

\section{Statistical analysis}

Data are expressed as the mean \pm SEM of three experiments. Differences between groups were analyzed by ANOVA followed by a Bonferroni's post-hoc test. Statistical significance was considered at $p<0.05$.

\section{RESULTS}

\section{Construction and purification of Tat-Trx 1 fusion protein}

We constructed a Tat-Trx1 fusion protein for Trx1 protein transduction by fusing human Trx1 gene in frame with Tat-peptide and His-tag. As a negative control, Trx1 gene was fused to His-tag alone (Fig. 1A). After the protein was overexpressed by IPTG indcution, Tat-Trx1 and Trx1 proteins were purified by Ni-NTA and PD-10 chromatography. By SDS-PAGE, one single band was detected for purified Tat-Trx1 or Trx1 protein at their expected molecular weights. Furthermore, both purified Tat-Trx1 and Trx1 proteins were identified by Western blotting using an anti-His antibody (Fig. 1B).

\section{Transduction of Tat-Trx1 protein into HT-22 cells}

Transduction of Tat-Trx1 protein was examined in HT-22 cells. These cells were treated with Tat-Trx1 protein $(0.5-5 \mu \mathrm{M})$ for $1 \mathrm{~h}$ or with Tat-Trx1 protein $(5 \mu \mathrm{M})$ at different time intervals 
A

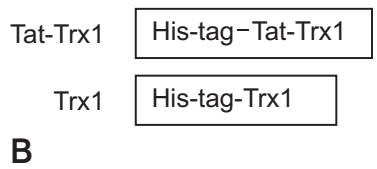

(kDa)

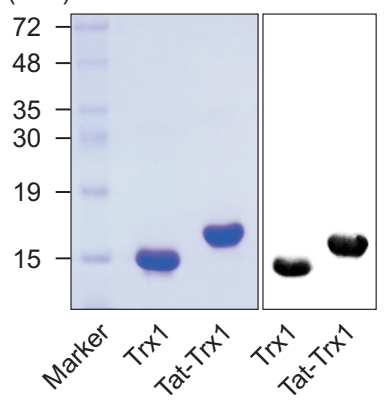

E
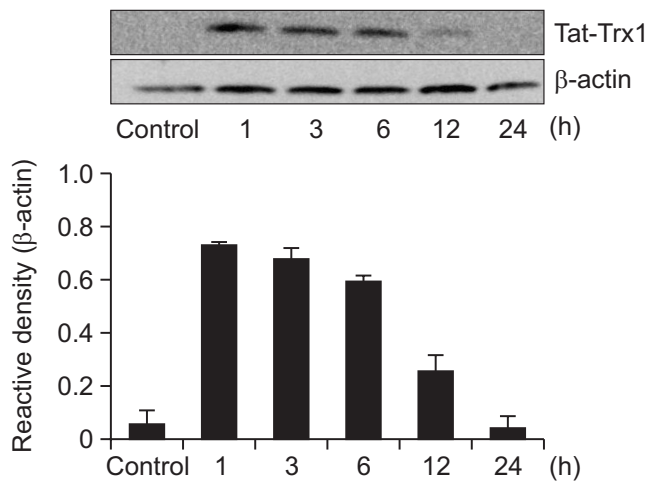

D
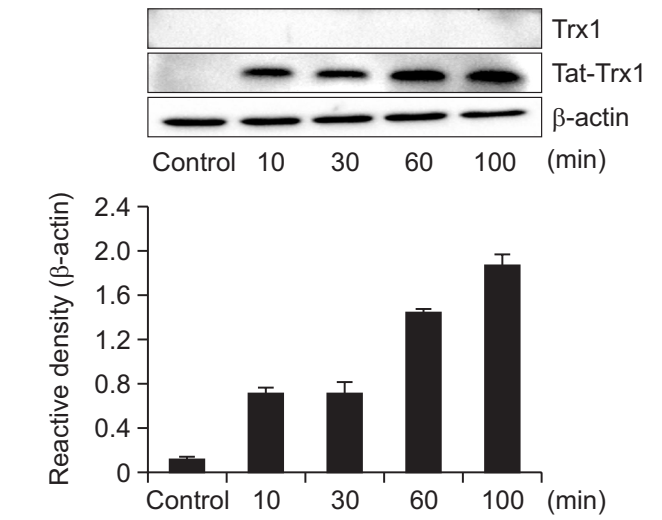

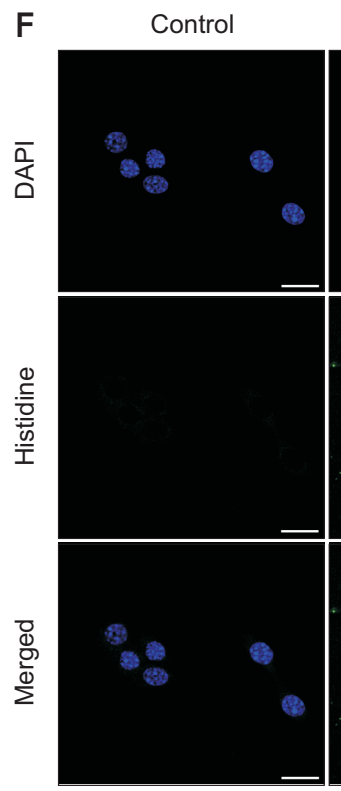

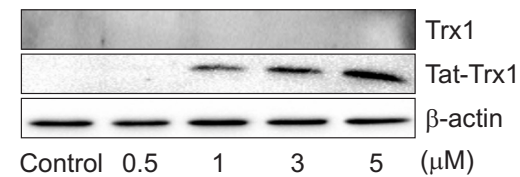

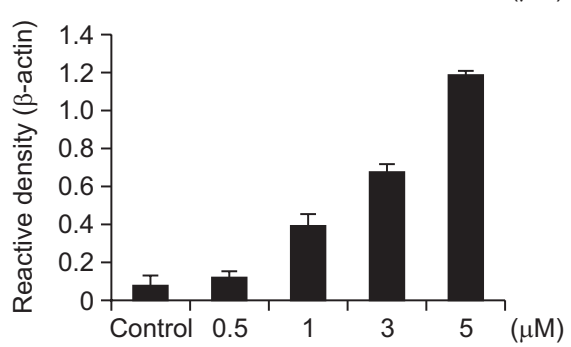

$\mu \mathrm{M})$ 
A
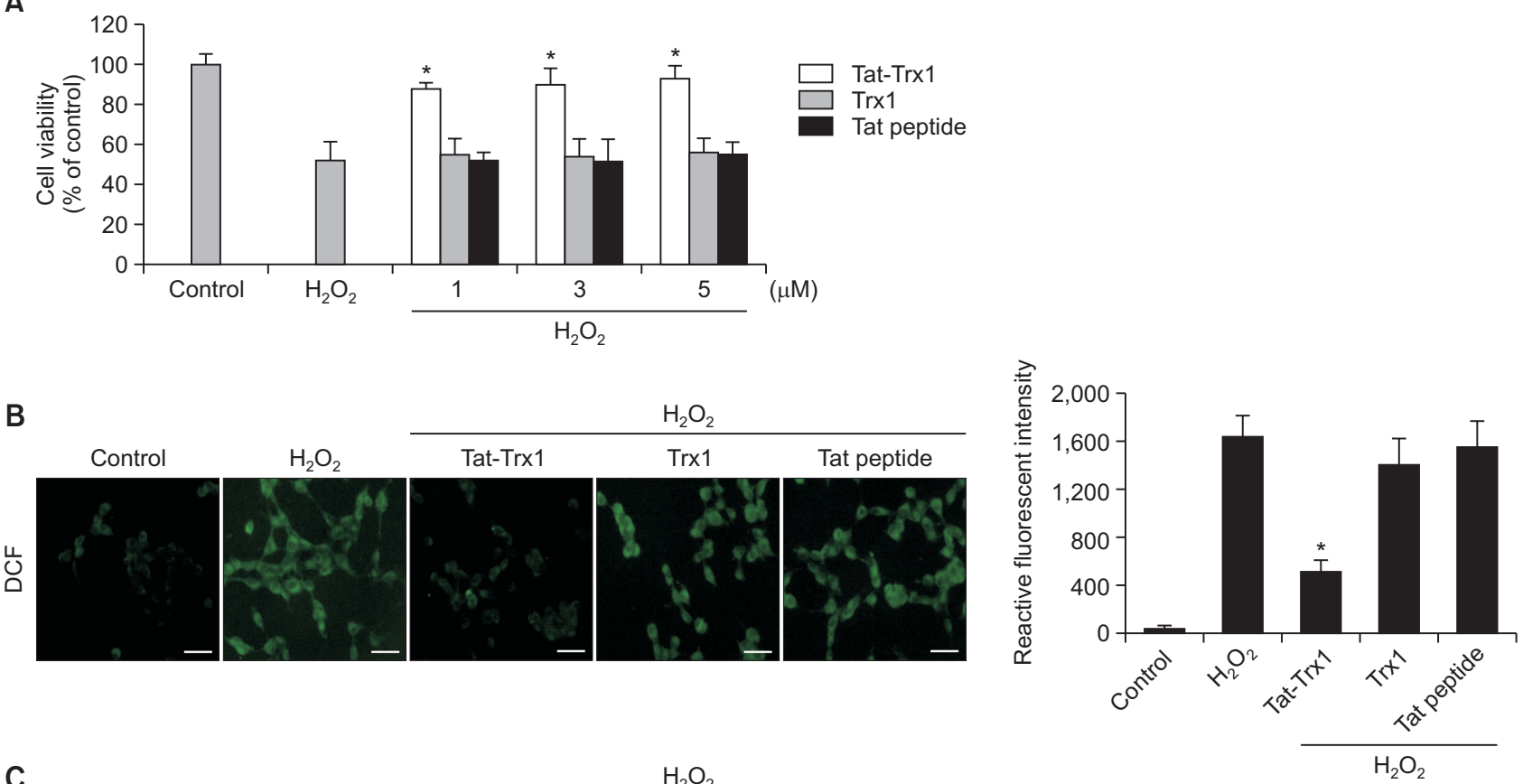

C
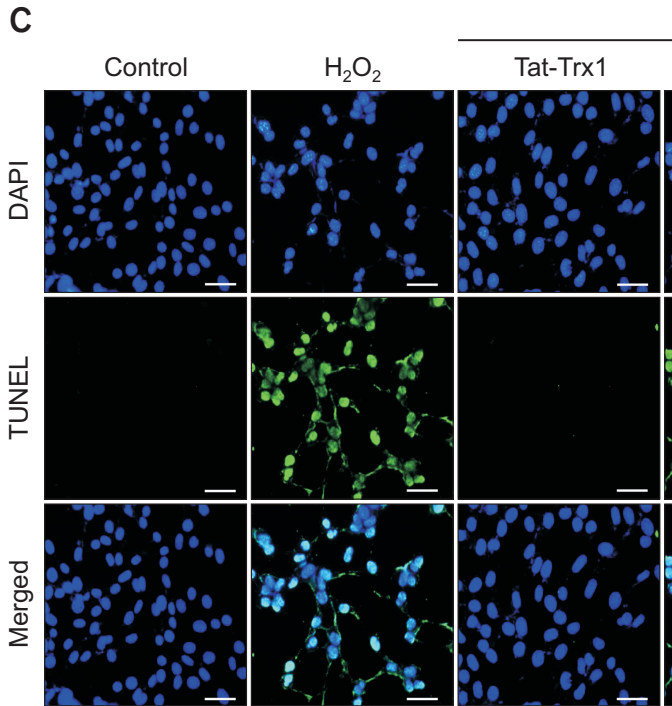

$\mathrm{H}_{2} \mathrm{O}_{2}$ Tat peptide

Fig. 2. Effects of transduced Tat-Trx1 protein on cell viability in response to oxidative stress. (A) Effect of transduced Tat-Trx1 protein on cell viability. HT-22 cells were pretreated with Tat-Trx1 protein $(1-5 \mu \mathrm{M})$ for $1 \mathrm{~h}$ and exposed to $\mathrm{H}_{2} \mathrm{O}_{2}(700 \mu \mathrm{M})$ for $1 \mathrm{~h} 30 \mathrm{~min}$. Cell viabilities were estimated using a colorimetric assay using WST-1. Effects of Tat-Trx1 protein on $\mathrm{H}_{2} \mathrm{O}_{2}$-induced ROS production and DNA damage. Treatment with Tat-Trx1 protein $(5 \mu \mathrm{M})$ and Trx1 protein was followed by $1 \mathrm{~h}$ treatment with $\mathrm{H}_{2} \mathrm{O}_{2}(700 \mu \mathrm{M})$. Intracellular ROS levels were measured by (B) DCF-DA staining and (C) DNA fragmentation was detected by TUNEL staining. The fluorescence intensity was measured by ELISA plate reader; scale bar=50 $\mu \mathrm{m}$. The bars in the figure represent the mean \pm SEM obtained from 3 independent experiments. ${ }^{*} p<0.05$ compared with $\mathrm{H}_{2} \mathrm{O}_{2}$-treated cells.

To determine effects of Tat-Trx1 protein on oxidative stress, ROS generation and DNA fragmentation in $\mathrm{H}_{2} \mathrm{O}_{2}$ exposed $\mathrm{HT}$ 22 cells were assessed. As shown in Fig. $2 \mathrm{~B}$ and $2 \mathrm{C}$, levels of ROS generation and DNA fragmentation were markedly reduced in Tat-Trx1 protein treated cells as compared with $\mathrm{H}_{2} \mathrm{O}_{2}$ only exposed cells. However, they showed no significant difference between $\mathrm{H}_{2} \mathrm{O}_{2}$ alone treated cells and Trx1 protein or Tat peptide treated cells. These results indicate that transduced Tat-Trx1 protein can inhibit cell death caused by oxidative stress by decreasing ROS generation and DNA fragmen- tation.

\section{Protective mechanism of Tat-Trx1 against oxidative stress- induced cell death}

The cascade of ASK1 and MAPKs has emerged as a key cell death pathway in response to oxidative stress (Ichijo et al., 1997; Shiizaki et al., 2013). We determined effects of Tat-Trx1 on ASK1 and MAPKs signaling pathways. ASK1 and MAPKs (p38, JNK, and EKR) were markedly activated in $\mathrm{H}_{2} \mathrm{O}_{2}$ only exposed HT-22 cells compared to those in control cells. In 
A

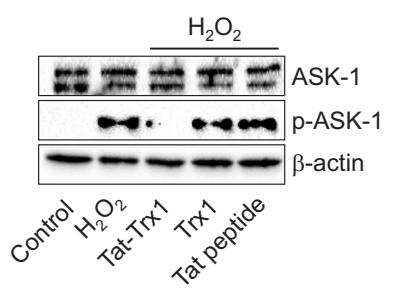

B

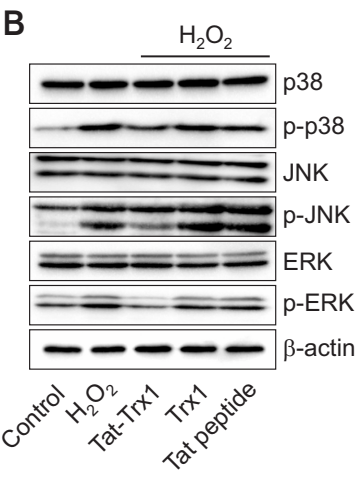

C

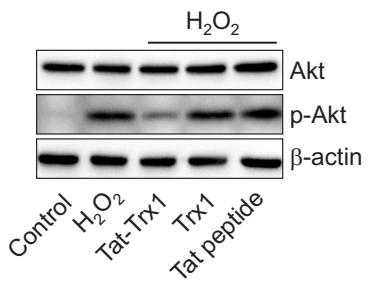

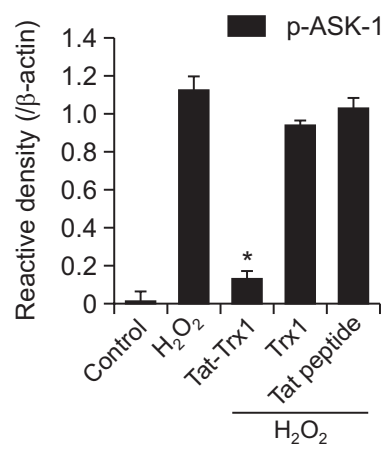
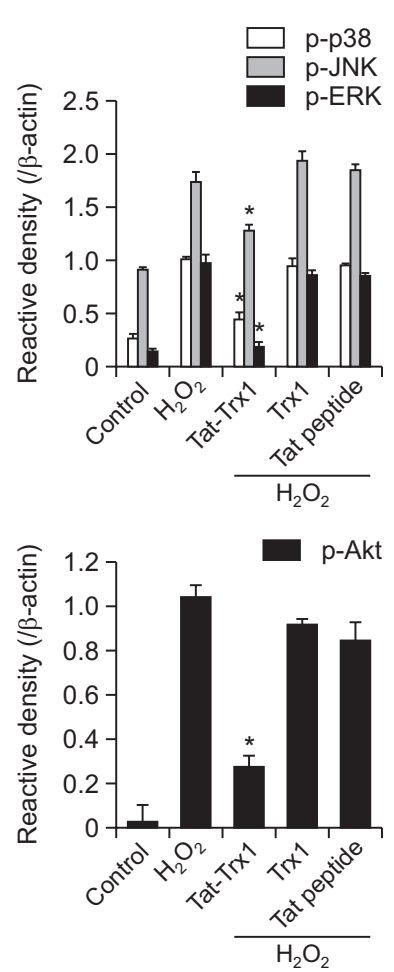

D

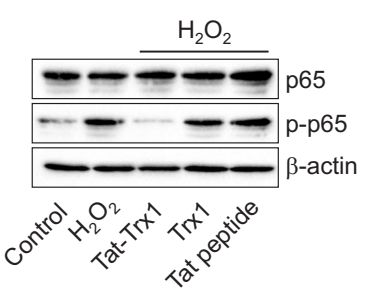

E
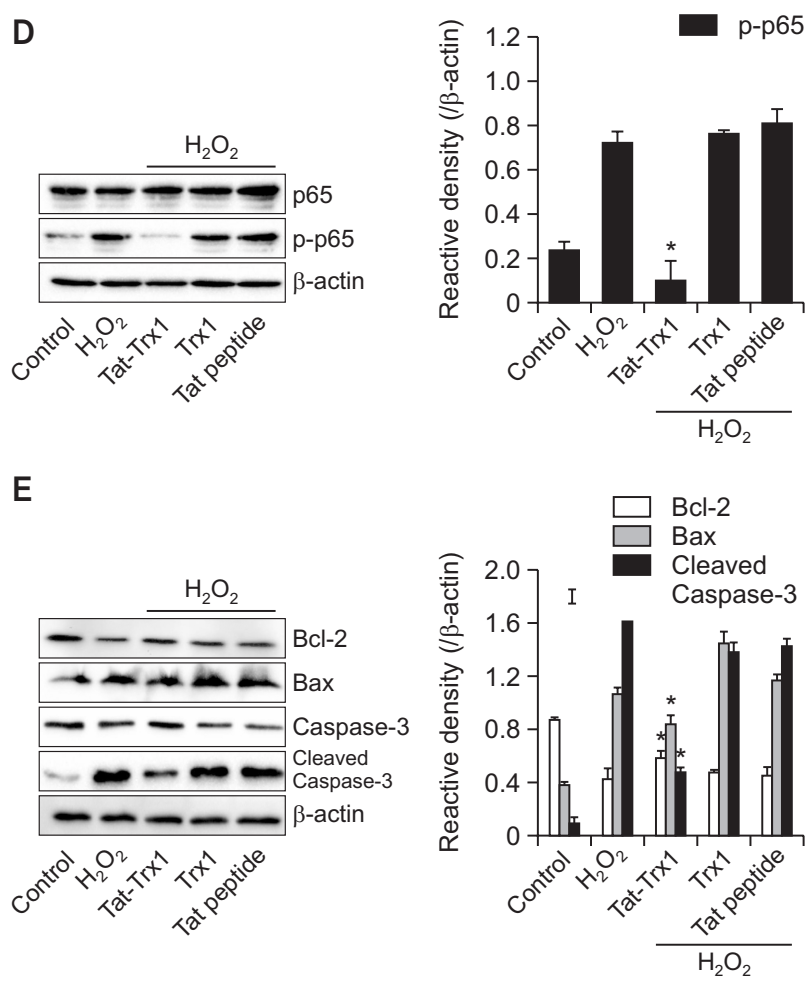

Fig. 3. Effect of Tat-Trx1 protein against $\mathrm{H}_{2} \mathrm{O}_{2}$-induced cellular signaling pathways in HT-22 cells. One-hour pretreatment of HT22 cells with Tat-Trx1 protein $(5 \mu \mathrm{M})$ or Trx 1 protein was followed by treatment with $\mathrm{H}_{2} \mathrm{O}_{2}(700 \mu \mathrm{M})$. Then, the expression levels of $(\mathrm{A})$ ASK1, (B) MAPK, (C) Akt, (D) p65 and (E) Bcl-2, Bax, Caspase-3 and cleaved Caspase- 3 were determined by Western blotting. Band intensity was measured by densitometer. The bars in the figure represent the mean \pm SEM obtained from 3 independent experiments. ${ }^{*} p<0.05$ compared with $\mathrm{H}_{2} \mathrm{O}_{2}$-treated cells. cells treated with Trx1 protein or Tat peptide, phosphorylation levels of ASK1 and MAPKs were not significantly changed. In contrast, Tat-Trx1 protein markedly reduced $\mathrm{H}_{2} \mathrm{O}_{2}$-induced phosphorylation of ASK1 and MAPKs (Fig. 3A, 3B).

To explore cellular mechanisms underlying the protective effect of Tat-Trx1 protein, we investigated expression levels of Akt, p65, and apoptotic related proteins in $\mathrm{H}_{2} \mathrm{O}_{2}$ exposed HT22 cells. Phosphorylation levels of Akt and p65 were reduced in Tat-Trx1 protein treated cells. However, their levels were unchanged in Trx1 protein or Tat peptide treated cells (Fig. 3C, 3D). Tat-Trx1 protein increased expression levels of Bcl-2 and Caspase- 3 in $\mathrm{H}_{2} \mathrm{O}_{2}$ treated HT-22 cells. In contrast, expression levels of Bax and cleaved Caspase- 3 showed opposite patterns compared to $\mathrm{Bcl}-2$ and Caspase-3 expression (Fig. 3E). These results indicate that Tat-Trx1 protein can inhibit HT-22 cell death by modulating the expression of ASK1, MAPKs, and apoptotic proteins.

\section{Protective effect of Tat-Trx1 protein against ischemic injury}

To investigate effects of Tat-Trx1 protein against ischemic injury in an animal model, we performed immunohistochemistry. As shown in Fig. 4A, Tat-Trx1 protein significantly protected neuronal cell death in the hippocampal CA1 region. However, both Trx1 protein and Tat peptide treated groups showed a similar pattern compared with vehicle treated group. We also examined whether Tat-Trx1 protein inhibited the activation of microglia and astrocytes using F-JB, Iba-1, and GFAP staining, respectively (Fig. 4B). In the vehicle-, Trx1 protein, and Tat peptide protein-treated groups, F-JB, Iba-1, and GFAP fluorescence signals were intensively detected in the hippocampal CA1 region. In contrast, intensive fluorescence signals were markedly reduced in Tat-Trx1 protein treated group. These results indicate that Tat-Trx1 protein could protect against neuronal cell damage resulting from ischemic injury by decreasing microglia and astrocyte activation.

\section{Effects of Tat-Trx 1 protein on oxidative stress in an ischemic injury model}

To examine whether Tat-Trx1 protein could inhibit ischemiainduced oxidative stress, we performed DHE and 4-HNE to determine ROS generation and lipid peroxidation levels in 
A

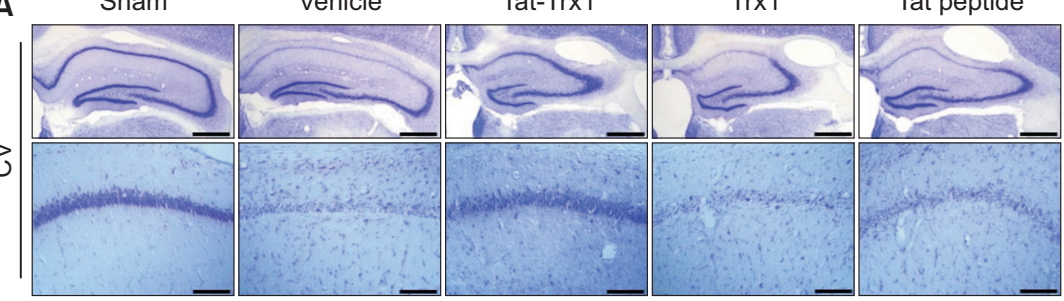

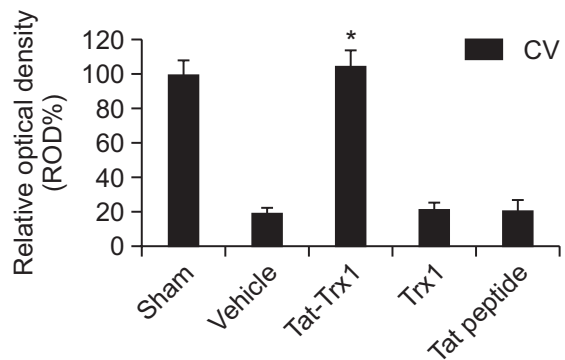

B

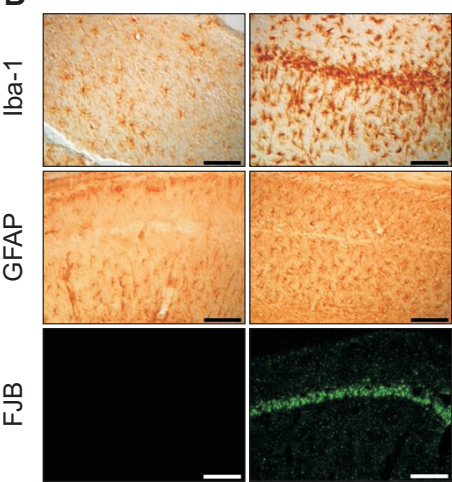

Tat-Trx1
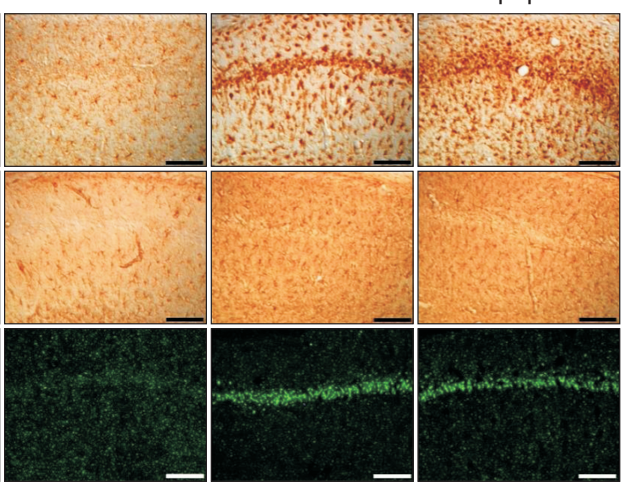

D

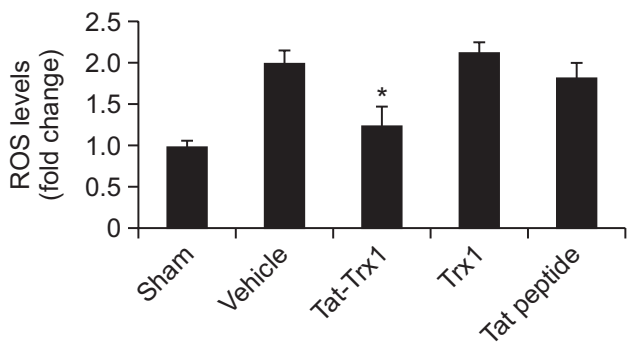

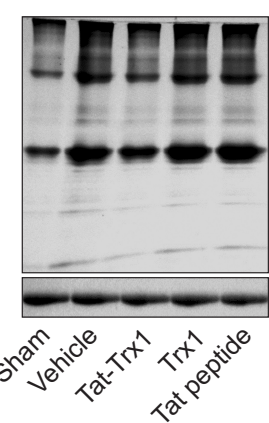

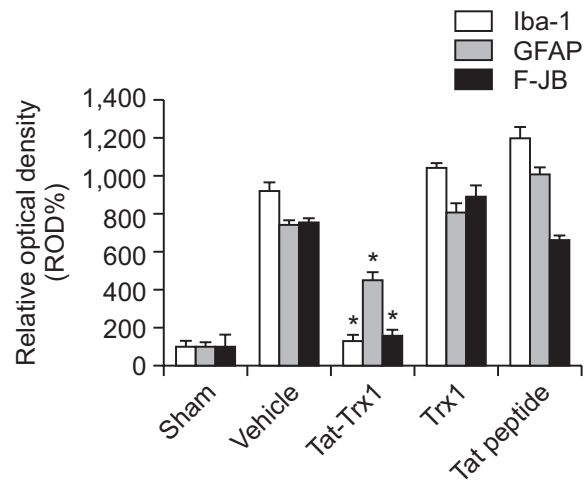

$\mathrm{E}$

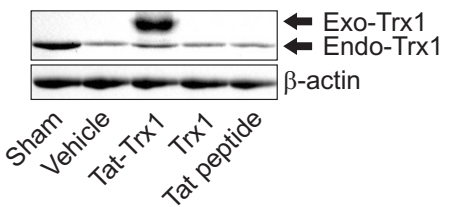

Fig. 4. Protective effects of transduced Tat-Trx1 protein on ischemic injury. Gerbils were treated with single injections Tat-Trx1 (2 mg/kg) proteins and killed after 7 days ( $\mathrm{n}=10$ per groups). Then, the effects of transduced Tat-Trx1 protein on neuronal cell viability after ischemic insults using immunostaining. (A) The hippocampus was stained with CV and (B) Iba-1, GFAP, F-JB in sham-, vehicle-, Tat-Trx1-, Trx1and Tat peptide-treated animals 7 days after I/R. Relative numeric analysis of CV-, Iba-1-, GFAP- and F-JB-positive neurons in CA1 region. Scale bar=400 and $50 \mu \mathrm{m}$. The brains from each group were harvested. (C) The intracellular ROS level was measured using an ROS assay kit. (D, E) Analysis of HNE and endogenous Trx1 protein levels. The levels of 4-HNE and endogenous Trx1 protein in the brain were analyzed by Western blot analysis using a 4-HNE and Trx1 antibody. ${ }^{*} p<0.05$, significantly different from the vehicle group.

an ischemic injury animal model. As shown in Fig. 4C and $4 \mathrm{D}$, levels of ROS and lipid peroxidation were significantly increased in vehicle-, Trx1 protein-, and Tat peptide-treated groups compared with the sham control group. In contrast, Tat-Trx1 protein treated group reduced ischemia-induced ROS and lipid peroxidation levels. We also determined endogenous Trx1 protein expression levels. Compared with the vehicle group, endogenous Trx1 protein levels were similar in other treatment groups (Fig. 4E). These results indicate that Tat-Trx1 protein plays a role in reducing ischemia-induced cell damage by inhibiting oxidative stress in an ischemic injury animal model.

\section{DISCUSSION}

Thioredoxin $1(\operatorname{Tr} x 1)$ is a multifunctional protein with MW of $12 \mathrm{kDa}$. It is expressed in all living cells including prokaryotic and eukaryotic cells. Trx1 has two redox-active cysteine residues within a conserved active site having a sequence of CysGly-Pro-Cys. It plays key roles in cellular growth, regulation of gene expression, and apoptosis (Susanti et al., 2014; Booze et al., 2016). Several studies have shown that Trx1 protein can act as an antioxidant protein and inhibit cell death caused by oxidative stress (Saitoh et al., 1998; Ueda et al., 2002; Yoshida et al., 2003; Nadeau et al., 2007). In addition, several reports have shown that oxidative stress induced by ROS contributes to various ischemia-induced tissue injuries including those to the brain, heart, and liver (Floyd, 1990; Chan, 2001; 
Sugawara and Chan, 2003; Leak et al., 2015). However, functional roles and precise protective mechanisms of Trx1 protein on ischemia remain unclear.

We showed that Tat-Trx1 protein transduced into HT-22 cells and markedly inhibited HT-22 cell death, ROS generation, and DNA fragmentation caused by oxidative stress. Recent studies have shown that knockdown of Trx1 can decrease astrocyte cell viability in an oxygen glucose deprivation/reperfusion (OGD/R)-induced cell model, suggesting that Trx1 can protect astrocyte cells from oxidative stress by exerting anti-oxidant effects (Wang et al., 2016). Overexpression of Trx1 protein can significantly protect against progressive $\beta$-cell failure in a T2DM animal model (Stosic-Grujicic et al., 2008). Overexpression of Trx1 protein can also reduce hyperglycemia in pancreatic islets of an STZ-induced T1DM animal model by triggering an anti-oxidant effect (Yamamoto et al., 2008). These results suggest that Trx1 protein can protect pancreatic $\beta$-cell function against oxidative stress in both T2DM and T1DM. In addition, Trx1 protein can act as a radical scavenger under oxidative stress conditions and DNA damage is markedly higher in Trx1 knockdown human PKO cells after exposure of $\mathrm{N}$-Nitroso- $\mathrm{N}$ methylurea (NMU) (Das and Das, 2000; Kim et al., 2013). In this study, we also demonstrated that Tat-Trx1 protein could inhibit HT-22 cell death caused by oxidative stress, indicating that this protein could act an antioxidant protein.

Several studies have demonstrated that excessive ROS play a key role in ischemic injury and that ROS are associated with the induction of MAPKs, NF- $\mathrm{KB}$, and Akt activation in neuronal cells (Kwon et al., 2011; Zhu et al., 2017; Jia et al., 2018). It has been well described that Trx1 can regulate the redox functions of various signal molecules involved in transduction pathway including NF-kB, p53, ASK-1, Akt, and MAPKs (Meuillet et al., 2004; Kaimul Ahsan et al., 2005; Nakamura et al., 2006; Fujino et al., 2007). We showed that Tat-Trx1 protein markedly inhibited against $\mathrm{H}_{2} \mathrm{O}_{2}$-induced activation of ASK-1, MAPKs, Akt, and NF-kB in HT-22 cells. Wu et al. (2015) have shown that inhibition of Trx1 with siRNA can increase phosphorylation levels of ASK1, JNK, and p38 expression in middle cerebral artery occlusion (MCAO) rats, suggesting that Trx1 can protect against neuronal cell death via inhibition of the ASK1-JNK/p38 signaling pathway. It is well known that ASK1 is a member of the MAP3 kinase family that can activate JNK and p38 kinase pathways. It is activated by various stimuli including oxidative stress (Ichijo et al., 1997; Shiizaki et al., 2013). Lee et al. (2012) have shown that phosphorylation of ASK1 is increased in MPP or $^{+} \mathrm{H}_{2}$ treated SH-SY5Y cells and MPTP exposed mice dopaminergic cells. Other studies also have suggested that inhibiting MAPKs and NF- $\mathrm{\kappa B}$ activation is a plausible therapeutic strategy against ischemic injury (Yu et al., 2016; Li et al., 2017). Akt plays a critical role in cell survival and protects against apoptosis. Oxidative stressinduced phosphorylation of Akt (ser-473) can activate apoptosis and subsequent neuronal cell death (Yano et al., 2001). Furthermore, other studies have demonstrated that oxidative stress-induced cellular damage is mediated by activation of PI3K/Akt signaling pathway in neuronal cells (Angeloni et al., 2011; Mo et al., 2012).

Next, we examined effects of Tat-Trx1 protein against $\mathrm{H}_{2} \mathrm{O}_{2}$ induced apoptotic cell death. Tat-Trx1 protein markedly inhibited Bax and cleaved Caspase- 3 expression, whereas Tat-Trx1 protein increased $\mathrm{Bcl}-2$ and Caspase-3 expression in $\mathrm{H}_{2} \mathrm{O}_{2}$ exposed HT-22 cells. In Trx1 knockdown EMT6 cells, cleaved
Caspase-3 expression is markedly increased, meaning that knockdown of Trx1 can increase apoptosis and cell death (Yoo et al., 2013). Zhang et al. (2004) have shown that activation of ASK1 by TNF can activate pro-apoptotic proteins, leading to cell death in Trx knockdown endothelial cells. Although the precise mechanism remains to be elucidated, Tat-Trx1 protein protects against $\mathrm{H}_{2} \mathrm{O}_{2}$-induced $\mathrm{HT}-22$ cell death by inhibiting ASK1 and MAPKs activation and by regulating the apoptotic signaling pathway.

We further investigated the effect of Tat-Trx1 protein on ischemic insults using an animal ischemia model. Tat-Trx1 protein markedly inhibited neuronal cell death and reduced astrocytes and microglia activation in the ischemic animal model. In a previous study, we have shown that various PTDs fused with proteins can transduce into animal ischemia model brain and inhibit neuronal cell death (Shin et al., 2014; Yeo et al., 2019). Other studies have also demonstrated that microglial and astrocyte activation markedly increased during ischemic injury. Thus, the activation of microglial and astrocytes is considered as a key phenomenon of ischemic neuronal injury (Ito et al., 2001; Chen and Swanson, 2003; Angeloni et al., 2011). Overexpression of Trx1 protein can also reduce infarct size in a mouse model of ischemia reperfusion, suggesting that Trx1 protein may be a useful therapeutic tool for ischemia reperfusion injury (Tao et al., 2004). Janac et al. (2006) have shown that occlusion of common carotid artery (CCA) can increase neuronal damage in the hippocampus, striatum, and neocortex known to be involved in the control of locomotor and stereotypic activities. Several studies have reported that chronic diffuse cerebral ischemia models are important for understanding the correlation between chronic cerebral hypoperfusion and cognitive functions. Chronic cerebral hypoperfusion causes white matter degeneration and neuronal degradation of the hippocampal CA1 regions and triggers oxidative stress in animal models. These brain damages can lead to spatial learning and memory impairment (Shibata et al., 2004; Yoshizaki et al., 2008; Miki et al., 2009; Luo et al., 2015). Other studies have shown significantly impairment in spatial learning and memory in the occlusion of CCA group compared with the sham group and suggested that further studies are warranted to understand mechanisms of brain dysfunction and impairment and to assess the efficacy of therapeutic agents for treating neurological disorders (Mehla et al., 2018; Mansour et al., 2019). Although further experiments are needed to understand behavioral, spatial learning, and memory impairment, we showed that Tat-Trx1 protein plays a key role in hippocampal neuronal cell death in vitro and in vivo. The exact mechanisms of neuronal damage in ischemia remain to be explored.

In summary, we demonstrated that Tat-Trx1 protein transduced into HT-22 cells and significantly inhibited oxidative stress-induced cell death. In addition, Tat-Trx1 protein prevented hippocampal neuronal cell death in an animal ischemia model. Our resutls suggest that Tat-Trx 1 protein may represent a potential therapeutic strategy against brain ischemic injury.

\section{CONFLICT OF INTEREST}

The authors declare no conflict of interest. 


\section{ACKNOWLEDGMENTS}

This research was supported by Basic Science Research Program (2018R1D1A3B07049265 \& 2019R1A6A1A11036849) through the National Research Foundation of Korea (NRF) funded by the Ministry of Education.

\section{REFERENCES}

Ang, Y. L., Yong, W. P. and Tan, P. (2016) Translating gastric cancer genomics into targeted therapies. Crit. Rev. Oncol. Hematol. 100, 141-146.

Angeloni, C., Motori, E., Fabbri, D., Malaguti, M., Leoncini, E., Lorenzini, A. and Hrelia, S. (2011) $\mathrm{H}_{2} \mathrm{O}_{2}$ preconditioning modulates phase II enzymes through p38 MAPK and PI3K/Akt activation. Am. J. Physiol. Heart Circ. Physiol. 300, H2196-H2205.

Booze, M. L., Hansen, J. M. and Vitiello, P. F. (2016) A novel mouse model for the identification of thioredoxin-1 protein interactions. Free Radic. Biol. Med. 99, 533-543.

Bradford, M. M. (1976) A rapid and sensitive method for the quantitation of microgram quantities of protein utilizing the principle of protein-dye binding. Anal. Biochem. 72, 248-254.

Chan, P. H. (2001) Reactive oxygen radicals in signaling and damage in the ischemic brain. J. Cereb. Blood Flow Metab. 21, 2-14.

Chen, Y. and Swanson, R. A. (2003) Astrocytes and brain injury. J. Cereb. Blood Flow Metab. 23, 137-149.

Das, K. C. and Das, C. K. (2000) Thioredoxin, a singlet oxygen quencher and hydroxyl radical scavenger: redox independent functions. Biochem. Biophys. Res. Commun. 277, 443-447.

Embury, J., Klein, D., Pileggi, A., Ribeiro, M., Jayaraman, S., Molano, R. D., Fraker, C., Kenyon, N., Ricordi, C., Inverardi, L. and Pastori, R. L. (2001) Proteins linked to a protein transduction domain efficiently transduce pancreatic islets. Diabetes 50, 1706-1713.

Floyd, R. A. (1990) Role of oxygen free radicals in carcinogenesis and brain ischemia. FASEB J. 4, 2587-2597.

Fujino, G., Noguchi, T., Matsuzawa, A., Yamauchi, S., Saitoh, M., Takeda, K. and Ichijo, H. (2007) Thioredoxin and TRAF family proteins regulate reactive oxygen species-dependent activation of ASK1 through reciprocal modulation of the $\mathrm{N}$-terminal homophilic interaction of ASK1. Mol. Cell Biol. 27, 8152-8163.

Ginsberg, M. D., Becker, D. A., Busto, R., Belayev, A., Zhang, Y., Khoutorova, L., Ley, J. J., Zhao, W. and Belayev, L. (2003) Stilbazulenyl nitrone, a novel antioxidant, is highly neuroprotective in focal ischemia. Ann. Neurol. 54, 330-342.

Haendeler, J., Hoffmann, J., Tischler, V., Berk, B. C., Zeiher, A. M. and Dimmeler, S. (2002) Redox regulatory and anti-apoptotic functions of thioredoxin depend on S-nitrosylation at cysteine 69. Nat. Cell Biol. 4, 743-749.

Ichijo, H., Nishida, E., Irie, K., ten Dijke, P., Saitoh, M., Moriguchi, T., Takagi, M., Matsumoto, K., Miyazono, K. and Gotoh, Y. (1997) Induction of apoptosis by ASK1, a mammalian MAPKKK that activates SAPK/JNK and p38 signaling pathways. Science 275, 90-94.

Ito, D., Tanaka, K., Suzuki, S., Dembo, T. and Fukuuchi, Y. (2001) Enhanced expression of Iba1, ionized calcium-binding adapter molecule 1 , after transient focal cerebral ischemia in rat brain. Stroke 32, 1208-1215.

Janac, B., Radenovic, L., Selakovic, V. and Prolic, Z. (2006) Time course of motor behavior changes in Mongolian gerbils submitted to different durations of cerebral ischemia. Behav. Brain Res. 175, 362-373.

Jegal, M. E., Jung, S. Y., Han, Y. S. and Kim, Y. J. (2019) C-terminal truncated $\mathrm{HBx}$ reduces doxorubicin cytotoxicity via ABCB1 upregulation in Huh-7 hepatocellular carcinoma cells. BMB Rep. 52, 330335.

Jellinger, K. A. and Stadelmann, C. (2001) Problems of cell death in neurodegeneration and Alzheimer's disease. J. Alzheimers Dis. 3, 31-40.

Jia, L., Chen, Y., Tian, Y. H. and Zhang, G. (2018) MAPK pathway mediates the anti-oxidative effect of chicoric acid against cerebral ischemia-reperfusion injury in vivo. Exp. Ther. Med. 15, 1640-1646. Kaimul Ahsan, M., Nakamura, H., Tanito, M., Yamada, K., Utsumi, H. and Yodoi, J. (2005) Thioredoxin-1 suppresses lung injury and apoptosis induced by diesel exhaust particles (DEP) by scavenging reactive oxygen species and by inhibiting DEP-induced downregulation of Akt. Free Radic. Biol. Med. 39, 1549-1559.

Kamimoto, Y., Sugiyama, T., Kihira, T., Zhang, L., Murabayashi, N., Umekawa, T., Nagao, K., Ma, N., Toyoda, N., Yodoi, J. and Sagawa, N. (2010) Transgenic mice overproducing human thioredoxin-1, an antioxidative and anti-apoptotic protein, prevents diabetic embryopathy. Diabetologia 53, 2046-2055.

Kim, D. H., Kim, H. M., Huong, P. T. T., Han, H. J., Hwang, J., Cha-Molstad, H., Lee, K. H., Ryoo, I. J., Kim, K. E., Huh, Y. H., Ahn, J. S., Kwon, Y. T., Soung, N. K. and Kim, B. Y. (2019) Enhanced anticancer effects of a methylation inhibitor by inhibiting a novel DNMT1 target, CEP 131, in cervical cancer. BMB Rep. 52, 342-347.

Kim, D. W., Shin, M. J., Choi, Y. J., Kwon, H. J., Lee, S. H., Lee, S., Park, J., Han, K. H., Eum, W. S. and Choi, S. Y. (2018) Tat-ATOX1 inhibits inflammatory responses via regulation of MAPK and NFkappaB pathways. BMB Rep. 51, 654-659.

Kim, E. K. and Choi, E. J. (2010) Pathological roles of MAPK signaling pathways in human diseases. Biochim. Biophys. Acta 1802, 396405.

Kim, H. L., Koedrith, P., Lee, S. M., Kim, Y. J. and Seo, Y. R. (2013) Base excision DNA repair defect in thioredoxin-1 (Trx1)-deficient cells. Mutat. Res. 751-752, 1-7.

Kim, H. R., Kim, D. W., Jo, H. S., Cho, S. B., Park, J. H., Lee, C. H., Choi, Y. J., Yeo, E. J., Park, S. Y., Kim, S. T., Yu, Y. H., Kim, D. S., Kim, H. A., Cho, S. W., Han, K. H., Park, J., Eum, W. S. and Choi, S. Y. (2015) Tat-biliverdin reductase A inhibits inflammatory response by regulation of MAPK and NF-kappaB pathways in Raw 264.7 cells and edema mouse model. Mol. Immunol. 63, 355-366.

Kubo, E., Fatma, N., Akagi, Y., Beier, D. R., Singh, S. P. and Singh, D. P. (2008) TAT-mediated PRDX6 protein transduction protects against eye lens epithelial cell death and delays lens opacity. Am. J. Physiol. Cell Physiol. 294, C842-C855.

Kwon, S. H., Hong, S. I., Kim, J. A., Jung, Y. H., Kim, S. Y., Kim, H. C., Lee, S. Y. and Jang, C. G. (2011) The neuroprotective effects of Lonicera japonica THUNB. against hydrogen peroxide-induced apoptosis via phosphorylation of MAPKs and PI3K/Akt in SH-SY5Y cells. Food Chem. Toxicol. 49, 1011-1019.

Leak, R. K., Li, P., Zhang, F., Sulaiman, H. H., Weng, Z., Wang, G., Stetler, R. A., Shi, Y., Cao, G., Gao, Y. and Chen, J. (2015) Apurinic/apyrimidinic endonuclease 1 upregulation reduces oxidative DNA damage and protects hippocampal neurons from ischemic injury. Antioxid. Redox Signal. 22, 135-148.

Lee, K. W., Zhao, X., Im, J. Y., Grosso, H., Jang, W. H., Chan, T. W., Sonsalla, P. K., German, D. C., Ichijo, H., Junn, E. and Mouradian, M. M. (2012) Apoptosis signal-regulating kinase 1 mediates MPTP toxicity and regulates glial activation. PLOS ONE 7, e29935.

Li, Y., Xu, B., Xu, M., Chen, D., Xiong, Y., Lian, M., Sun, Y., Tang, Z., Wang, L., Jiang, C. and Lin, Y. (2017) 6-Gingerol protects intestinal barrier from ischemia/reperfusion-induced damage via inhibition of p38 MAPK to NF-kappaB signalling. Pharmacol. Res. 119, 137148.

Li, Y. and Zhang, Z. (2015) Gastrodin improves cognitive dysfunction and decreases oxidative stress in vascular dementia rats induced by chronic ischemia. Int. J. Clin. Exp. Pathol. 8, 14099-14109.

Li, Z., Wang, Y., Xie, Y., Yang, Z. and Zhang, T. (2011) Protective effects of exogenous hydrogen sulfide on neurons of hippocampus in a rat model of brain ischemia. Neurochem. Res. 36, 1840-1849.

Luo, P., Lu, Y., Li, C., Zhou, M., Chen, C., Lu, Q., Xu, X., He, Z. and Guo, L. (2015) Long-lasting spatial learning and memory impairments caused by chronic cerebral hypoperfusion associate with a dynamic change of HCN1/HCN2 expression in hippocampal CA1 region. Neurobiol. Learn. Mem. 123, 72-83.

Mansour, A., Niizuma, K., Rashad, S., Sumiyoshi, A., Ryoke, R., Endo, H., Endo, T., Sato, K., Kawashima, R. and Tominaga, T. (2019) A refined model of chronic cerebral hypoperfusion resulting in cognitive impairment and a low mortality rate in rats. J. Neurosurg. 131, 892-902.

Mates, J. M., Segura, J. A., Alonso, F. J. and Marquez, J. (2012) Oxi- 
dative stress in apoptosis and cancer: an update. Arch. Toxicol. 86, 1649-1665

Mehla, J., Lacoursiere, S., Stuart, E., McDonald, R. J. and Mohajerani, M. H. (2018) Gradual cerebral hypoperfusion impairs fear conditioning and object recognition learning and memory in mice: potential roles of neurodegeneration and cholinergic dysfunction. J. Alzheimers Dis. 61, 283-293.

Meuillet, E. J., Mahadevan, D., Berggren, M., Coon, A. and Powis, G. (2004) Thioredoxin-1 binds to the C2 domain of PTEN inhibiting PTEN's lipid phosphatase activity and membrane binding: a mechanism for the functional loss of PTEN's tumor suppressor activity. Arch. Biochem. Biophys. 429, 123-133.

Miki, K., Ishibashi, S., Sun, L., Xu, H., Ohashi, W., Kuroiwa, T. and Mizusawa, H. (2009) Intensity of chronic cerebral hypoperfusion determines white/gray matter injury and cognitive/ motor dysfunction in mice. J. Neurosci. Res. 87, 1270-1281.

Mo, L., Yang, C., Gu, M., Zheng, D., Lin, L., Wang, X., Lan, A., Hu, F. and Feng, J. (2012) PI3K/Akt signaling pathway-induced heme oxygenase-1 upregulation mediates the adaptive cytoprotection of hydrogen peroxide preconditioning against oxidative injury in PC12 cells. Int. J. Mol. Med. 30, 314-320.

Nadeau, P. J., Charette, S. J., Toledano, M. B. and Landry, J. (2007) Disulfide Bond-mediated multimerization of Ask1 and its reduction by thioredoxin-1 regulate $\mathrm{H}_{2} \mathrm{O}_{2}$-induced c-Jun $\mathrm{NH}_{2}$-terminal kinase activation and apoptosis. Mol. Biol. Cell 18, 3903-3913.

Nakamura, H., Masutani, H. and Yodoi, J. (2006) Extracellular thioredoxin and thioredoxin-binding protein 2 in control of cancer. Semin. Cancer Biol. 16, 444-451.

Saitoh, M., Nishitoh, H., Fujii, M., Takeda, K., Tobiume, K., Sawada, Y., Kawabata, M., Miyazono, K. and Ichijo, H. (1998) Mammalian thioredoxin is a direct inhibitor of apoptosis signal-regulating kinase (ASK) 1. EMBO J. 17, 2596-2606.

Schwarze, S. R., Ho, A., Vocero-Akbani, A. and Dowdy, S. F. (1999) In vivo protein transduction: delivery of a biologically active protein into the mouse. Science 285, 1569-1572.

Shibata, M., Ohtani, R., Ihara, M., Tomimoto, H. (2004) White matter lesions and glial activation in a novel mouse model of chronic cerebral hypoperfusion. Stroke 35, 2598-2603.

Shiizaki, S., Naguro, I. and Ichijo, H. (2013) Activation mechanisms of ASK1 in response to various stresses and its significance in intracellular signaling. Adv. Biol. Regul. 53, 135-144.

Shin, M. J., Kim, D. W., Lee, Y. P., Ahn, E. H., Jo, H. S., Kim, D. S., Kwon, O. S., Kang, T. C., Cho, Y. J., Park, J., Eum, W. S. and Choi, S. Y. (2014) Tat-glyoxalase protein inhibits against ischemic neuronal cell damage and ameliorates ischemic injury. Free Radic. Biol. Med. 67, 195-210.

Sinha, K., Das, J., Pal, P. B. and Sil, P. C. (2013) Oxidative stress: the mitochondria-dependent and mitochondria-independent pathways of apoptosis. Arch. Toxicol. 87, 1157-1180.

Stosic-Grujicic, S., Stojanovic, I., Maksimovic-Ivanic, D., Momcilovic, M., Popadic, D., Harhaji, L., Miljkovic, D., Metz, C., Mangano, K., Papaccio, G., Al-Abed, Y. and Nicoletti, F. (2008) Macrophage migration inhibitory factor (MIF) is necessary for progression of autoimmune diabetes mellitus. J. Cell. Physiol. 215, 665-675.

Sugawara, T. and Chan, P. H. (2003) Reactive oxygen radicals and pathogenesis of neuronal death after cerebral ischemia. Antioxid. Redox Signal. 5, 597-607.

Susanti, D., Wong, J. H., Vensel, W. H., Loganathan, U., DeSantis, R., Schmitz, R. A., Balsera, M., Buchanan, B. B. and Mukhopadhyay, B. (2014) Thioredoxin targets fundamental processes in a methane-producing archaeon, Methanocaldococcus jannaschii. Proc. Natl. Acad. Sci. U.S.A. 111, 2608-2613.

Tao, L., Gao, E., Bryan, N. S., Qu, Y., Liu, H. R., Hu, A., Christopher, T. A., Lopez, B. L., Yodoi, J., Koch, W. J., Feelisch, M. and Ma, X. L. (2004) Cardioprotective effects of thioredoxin in myocardial isch- emia and reperfusion: role of S-nitrosation [corrected]. Proc. Natl. Acad. Sci. U.S.A. 101, 11471-11476.

Ueda, S., Masutani, H., Nakamura, H., Tanaka, T., Ueno, M. and Yodoi, J. (2002) Redox control of cell death. Antioxid. Redox Signal. 4, 405-414.

van den Berg, A. and Dowdy, S. F. (2011) Protein transduction domain delivery of therapeutic macromolecules. Curr. Opin. Biotechnol. 22, 888-893.

Wadia, J. S. and Dowdy, S. F. (2002) Protein transduction technology. Curr. Opin. Biotechnol. 13, 52-56.

Wang, M., Zhu, K., Zhang, L., Li, L. and Zhao, J. (2016) Thioredoxin 1 protects astrocytes from oxidative stress by maintaining peroxiredoxin activity. Mol. Med. Rep. 13, 2864-2870.

Wu, X., Li, L., Zhang, L., Wu, J., Zhou, Y., Zhou, Y., Zhao, Y. and Zhao, J. (2015) Inhibition of thioredoxin-1 with siRNA exacerbates apoptosis by activating the ASK1-JNK/p38 pathway in brain of a stroke model rats. Brain Res. 1599, 20-31.

Yamamoto, M., Yamato, E., Toyoda, S., Tashiro, F., Ikegami, H., Yodoi, J. and Miyazaki, J. (2008) Transgenic expression of antioxidant protein thioredoxin in pancreatic beta cells prevents progression of type 2 diabetes mellitus. Antioxid. Redox Signal. 10, 43-49.

Yano, S., Morioka, M., Fukunaga, K., Kawano, T., Hara, T., Kai, Y., Hamada, J., Miyamoto, E. and Ushio, Y. (2001) Activation of Akt/ protein kinase $B$ contributes to induction of ischemic tolerance in the CA1 subfield of gerbil hippocampus. J. Cereb. Blood Flow Metab. 21, 351-360.

Yeo, H., Yeo, E. J., Shin, M. J., Choi, Y. J., Lee, C. H., Kwon, H. Y., Kim, D. W., Eum, W. S. and Choi, S. Y. (2018) Protective effects of Tat-DJ-1 protein against streptozotocin-induced diabetes in a mice model. BMB Rep. 51, 362-367.

Yeo, H. J., Shin, M. J., Yeo, E. J., Choi, Y. J., Kim, D. W., Kim, D. S. Eum, W. S. and Choi, S. Y. (2019) Tat-CIAPIN1 inhibits hippocampal neuronal cell damage through the MAPK and apoptotic signaling pathways. Free Radic. Biol. Med. 135, 68-78.

Yoo, M. H., Carlson, B. A., Gladyshev, V. N. and Hatfield, D. L. (2013) Abrogated thioredoxin system causes increased sensitivity to TNFalpha-induced apoptosis via enrichment of p-ERK $1 / 2$ in the nucleus. PLoS ONE 8, e71427.

Yoshida, T., Oka, S., Masutani, H., Nakamura, H. and Yodoi, J. (2003) The role of thioredoxin in the aging process: involvement of oxidative stress. Antioxid. Redox Signal. 5, 563-570.

Yoshizaki, K., Adachi, K., Kataoka, S., Watanabe, A., Tabira, T., Takahashi, K. and Wakita, H. (2008) Chronic cerebral hypoperfusion induced by right unilateral common carotid artery occlusion causes delayed white matter lesions and cognitive impairment in adult mice. Exp. Neurol. 210, 585-591.

Yu, H., Shi, L., Qi, G., Zhao, S., Gao, Y. and Li, Y. (2016) Gypenoside Protects cardiomyocytes against ischemia-reperfusion injury via the inhibition of mitogen-activated protein kinase mediated nuclear factor kappa B pathway in vitro and in vivo. Front. Pharmacol. 7, 148.

Zhang, J., Xia, J., Zhang, Y., Xiao, F., Wang, J., Gao, H., Liu, Y., Rong, S., Yao, Y., Xu, G. and Li, J. (2016) HMGB1-TLR4 signaling participates in renal ischemia reperfusion injury and could be attenuated by dexamethasone-mediated inhibition of the ERK/NF-kappaB pathway. Am. J. Transl. Res. 8, 4054-4067.

Zhang, R., Al-Lamki, R., Bai, L., Streb, J. W., Miano, J. M., Bradley, J. and Min, W. (2004) Thioredoxin-2 inhibits mitochondria-located ASK1-mediated apoptosis in a JNK-independent manner. Circ. Res. 94, 1483-1491.

Zhu, N., Cai, C., Zhou, A., Zhao, X., Xiang, Y. and Zeng, C. (2017) Schisandrin B prevents hind limb from ischemia-reperfusion-induced oxidative stress and inflammation via mapk/nf-kappaB pathways in rats. Biomed. Res. Int. 2017, 4237973. 